\title{
CHINA - GLOBALIZATION-WORLD EMPIRACAL ANALYSIS OF CONNECTIONS
}

\author{
Monika Hadaś-Dyduch ${ }^{1, \mathrm{a}, *}$ \\ ${ }^{1}$ University of Economics in Katowice Department of Statistical and Mathematical Method in \\ Economics 1 Maja 50, 40-287 Poland \\ amonika.dyduch@ue.katowice.pl \\ "Corresponding author
}

Cite as: HADAŚ-DYDUCH, M. (2019). China-Globalization world empirical analysis of connections, Ekonomicko-manazerske spektrum, 13(2), 81-88.

Available at: dx.doi.org/10.26552/ems.2019.2.81-88

\begin{abstract}
The aim of this paper is to analyze globalization in China in the context of comparative analysis with other countries. The analysis is based on the globalization index, which combines in one number: actual economic flows, economic restrictions, data on information flows, data on personal contact and data on cultural proximity. Trend analysis and long and short period dependencies in globalization are based on the DTW algorithm and wavelet analysis. A discrete wavelet was used for wavelet analysis of the time series studied. In the process of discrete wavelet transformation, the received signal is divided into so-called approximation and detail. The approximation is then subjected to a subsequent division into further approximation and detail, while details are not subject to further divisions. In this way, the signal is presented as the sum of the approximation of the last level and the details from all levels. The study was conducted on a group of 146 countries. In the article, globalization is understood as a process of interaction and integration among the people, companies, and governments of different nations, a process driven by international trade and investment and aided by information technology. This process has effects on the environment, culture, political systems, economic development and prosperity, and human physical well-being in societies around the world.
\end{abstract}

Keywords: globalization, integration, similarity, DTW, wavelet.

JEL Classification: B4, F59, F6

\section{Introduction}

Globalization "is a process of interaction and integration among the people, companies, and governments of different nations, a process driven by international trade and investment and aided by information technology. This process has effects on the environment, culture, political systems, economic development and prosperity, and human physical well-being in societies around the world" (Levin Institute, www.globalization101.org). In other words, globalization is an economic, political and social process that takes on various forms and covers diverse areas, including finance; markets and strategies, mainly competition; technology, research and development and knowledge; lifestyles, consumption patterns, and the consequences of the globalization of culture; the rule of law; and the political unification of the world. Following Clark (2000), Norris (2000), Keohane and Nye (2000) globalization is defined to be the process of creating networks of connections among actors at multi- 
continental distances, mediated through a variety of flows including that of people, information and ideas, capital, and goods. Globalization is conceptualized as a process that erodes national boundaries, integrates national economies, cultures, technologies and governance, and produces complex relations of mutual interdependence Clark (2000), Norris (2000), Keohane and Nye (2000), Hadaś-Dyduch (2017). Globalization is not new. "For thousands of years, people and, later, corporations have been buying from and selling to each other in lands at great distances, such as through the famed Silk Road across Central Asia that connected China and Europe during the Middle Ages. Likewise, for centuries, people and corporations have invested in enterprises in other countries. In fact, many of the features of the current wave of globalization are similar to those prevailing before the outbreak of the First World War in 1914. But policy and technological developments of the past few decades have spurred increases in cross-border trade, investment, and migration so large that many observers believe the world has entered a qualitatively new phase in its economic development. Since 1950, for example, the volume of world trade has increased by 20 times, and from just 1997 to 1999 flows of foreign investment nearly doubled, from $\$ 468$ billion to $\$ 827$ billion. Distinguishing this current wave of globalization from earlier ones, author Thomas Friedman has said that today globalization is 'farther, faster, cheaper, and deeper.", Dreher (2006).

\section{Methodology}

The aim of this paper is to analyze globalization in China in the context of comparative analysis with other countries. The analysis was based on the globalization index reflecting: actual economic flows, economic restrictions, data on information flows, data on personal contact and data on cultural proximity. The aim of the study is to identify states most similar to China in the context of globalization, and to determine whether the similarity is short-term or long-periodic. DTW and discrete wavelet analysis were used as a research tool. Wavelet transformation is a transformation similar to the Fourier transform. Both transformations are based on the use of the scalar product of the examined signal/s $(\mathrm{t})$ and the remaining part, called the "nucleus of transformation." The main difference between these transformations is this nucleus. Wavelet analysis consists of decomposing the signal using wavelets obtained through translation and dilation of the mother wavelet. The Fourier transform as a nucleus uses sinusoidal functions (i.e. periodic functions representing one frequency). In the case of wavelet transformation, the wavelet is a wavelet - a special function limited by certain requirements that must be met in order for it to be used for so-called multiresolution analysis Hadaś-Dyduch et al. (2016).

\subsection{Empirical material}

Research in the context of globalization was conducted in 146 countries. 145 countries were compared to China in the context of the pace and intensity of globalization. The research was based on the indicator of globalization, etc. The KOF Globalization Index. "The KOF Globalization Index measures the three main dimensions of globalization: economic, social and political. In addition to three indices measuring these dimensions, we calculate an overall index of globalization and sub-indices referring to actual economic flows, economic restrictions, data on information flows, data on personal contact, and data on cultural proximity. In constructing the indices of globalization, each of the variables introduced is transformed to an index on a scale of one to one hundred, where one hundred is the maximum 
value for a specific variable over the 1970-2014 period, and one is the minimum value. (Dreher, 2006). Higher values denote greater globalization. The index of Globalization for China, contains actual economic flows, economic restrictions, data on information flows, data on personal contact and data on cultural proximity. In the period 1970-2014 the index grew year on year by $2.83 \%$, while in the period 2000-2014, it grew on average year-on-year by only $0.69 \%$. In the period 1990-2000, meanwhile, the average index grew year on year by 4.4 $\%$. The largest increase in the index over the previous year occurred in 1990. At that time, the globalization index with the above-mentioned characteristics increased by $30 \%$ compared to 1989.

Figure 1: Index of China (a) and Poland (b) globalization in particular years of the research period.

a)

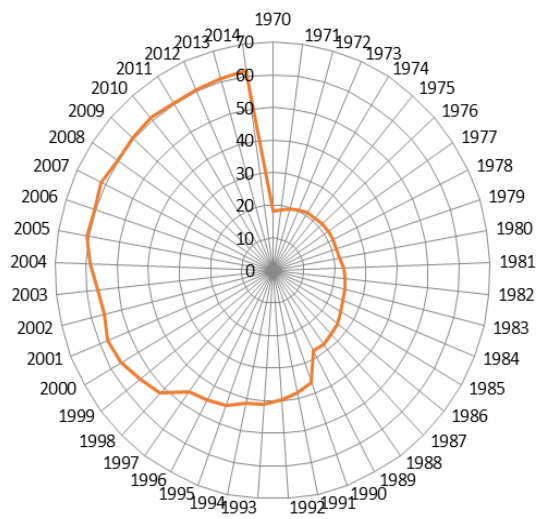

b)

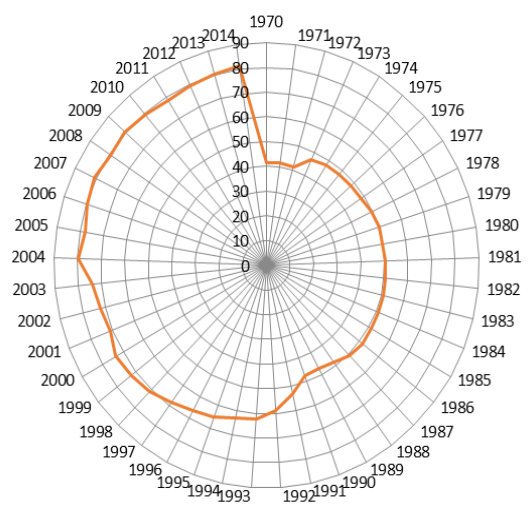

Source: own processing

\subsection{Research tool}

Research tools are DTW algorithm and discrete wavelet transform. The DTW algorithm was used to estimate the similarity of states in the context of globalization. Then to indicate the dependency time (ie short and long term relationships), wavelet analysis based on discrete wavelets was used. Wavelet analysis with applications has been widely described, among others, in the following positions: Cohen et al. (1993), Hadaś-Dyduch (2015a, 2015b, 2016a, 2016b, 2016c), Shensa (1992), Wickerhauser (1994). The dynamic time warping problem is stated as follows. Given two-time series $\mathrm{X}$, and $\mathrm{Y}$, of lengths $|\mathrm{X}|$ and $|\mathrm{Y}|$, construct a warp path $\mathrm{W}$ :

$$
\begin{gathered}
\mathrm{W}=w_{1}, w_{2}, \ldots, w_{K} \\
\max (|X|,|Y|) \leq K<|X|+|Y| \\
w_{k}=(i, j), w_{k+1}=\left(i^{\prime}, j^{\prime}\right) ; i \leq i^{\prime} \leq i+1 ; j \leq j^{\prime} \leq j+1
\end{gathered}
$$

The warp path must start at the beginning of each time series and finish at the end of both time series at $\mathrm{w} K=(|\mathrm{X}|,|\mathrm{Y}|)$. The optimal warp path is the minimum-distance warp path, where the distance of a warp path $\mathrm{W}$ is:

$$
\operatorname{Dist}(W)=\sum_{k=1}^{k=K} \operatorname{Dist}\left(w_{k i}, w_{k j}\right)
$$


Recurrence:

$$
D(i, j)=\operatorname{Dist}(i, j)+\min [D(i-1, j), D(i, j-1), D(i-1, j-1)] .
$$

\section{Results and Discussion}

Based on the calculations, the following results were obtained. The countries closest to China in terms of globalization are Honduras, Thailand, Indonesia, Paraguay, Moldova, Ecuador, Pakistan, Azerbaijan, India, Dominican Republic, the Republic of Korea, Albania, the Philippines, Colombia, and Mauritius. The countries least similar to China in globalization are Iceland, Qatar, Poland, Panama, Kuwait, Greece, the United Arab Emirates, Equatorial Guinea, Hungary, Portugal, Spain, Italy, New Zealand, Finland, Germany, the United States, Australia, France, Singapore, Norway, Luxembourg, Ireland, Austria, Sweden, Denmark, Switzerland, the United Kingdom, Canada, Belgium, and the Netherlands.

Figure 3: The scale of China's similarity with the least similar countries in terms of globalization

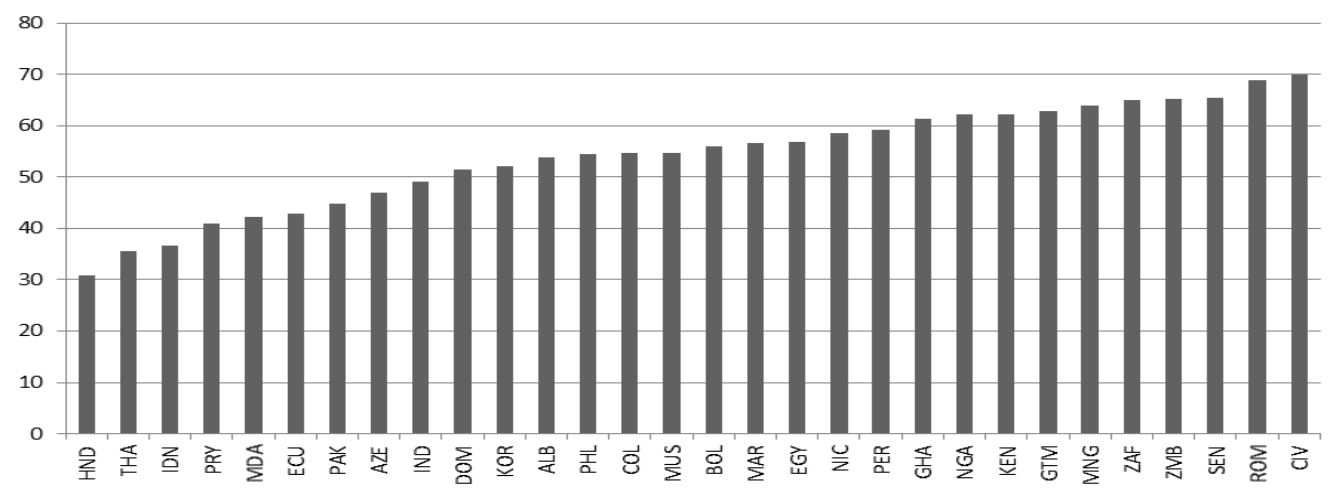

Source: Own processing

Figure 4: China's similarity with the most similar countries in terms of globalization



Source: Own processing

The analysis shows that the indicators that shape globalization, that is: actual economic flows, economic restrictions, data on information flows, data on personal contact and data on cultural proximity, reach a level most similar to the Chinese economy in Honduras, and least similar in the Netherlands. To determine what kind of relationship we are dealing with between China and Honduras, a five-level wavelet decomposition was made. The study uses the $\mathrm{db} 2$ wavelet. 
The results of the wavelet decomposition are shown in Figures 5, 6 and 7. It is clear from the wavelet decomposition that states have very similar long-term fluctuations (d5). There are also similar trends around the 5-year trend.

Figure 5: Results of wavelet decomposition for series, presenting compressed into one number, globalization for China



Source: Own processing

Figure 6: Results of wavelet decomposition for series, presenting compressed into one number, globalization for Honduras



Source: Own processing 
Figure 7: Results of wavelet decomposition for series, presenting compressed into one number, globalization for Netherland

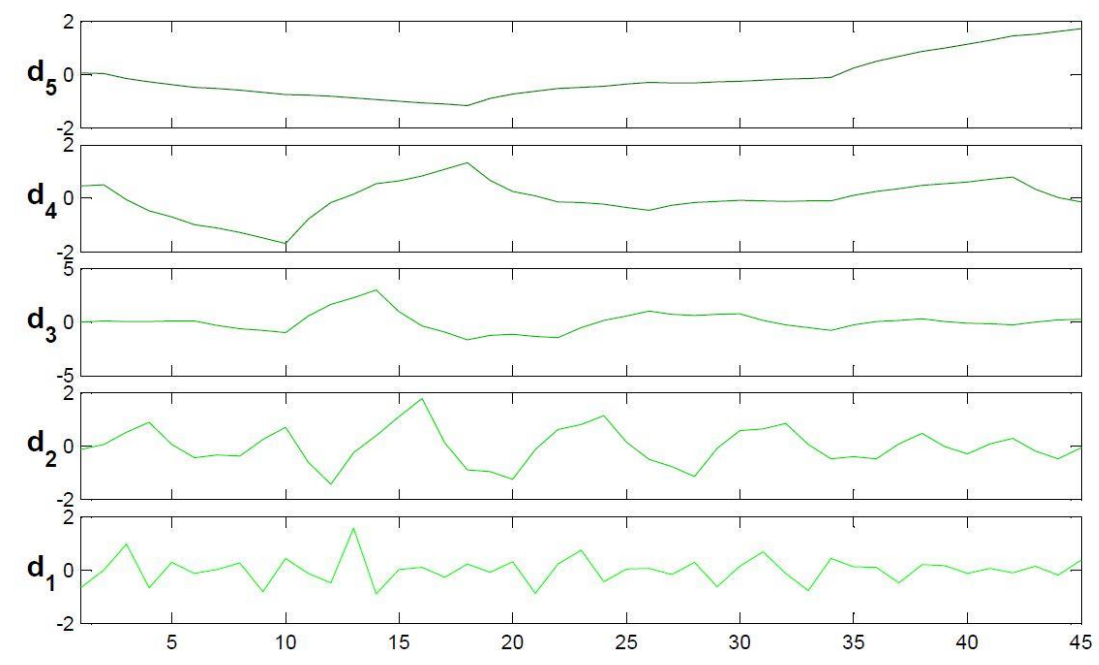

Source: Own processing

\section{Conclusion}

The study showed that for each of the 145 countries analyzed in relation to China, the globalization index operates in a different way and is characterized by a different degree of stability. However, despite the great diversity of economic, cultural and capital markets in the world, the closest to the Chinese economy in the context of globalization is Honduras. It should be noted that globalization is an important issue as it is a range of processes that coorganize our shared world. As you know, today's globalization is influenced by many significant factors, including constant scientific and technical progress, international competitiveness and the various economic policies of states. Free access to the Internet and social media, the use of modern technologies, the possibility of freer movement between countries and continents etc. have resulted in globalization becoming something natural, and the pursuit of it justified.

However, a lot of questions arise, for example, are we still open to globalization in times of mass migration and spreading terrorism? What should be done with favourable measures such as the IT revolution, and liberalization of capital flows? We are aware, to a greater or lesser extent, that globalization affects the creation of new or the evolution of existing processes, which we are unable to control completely, and which may be starting to show signs of pathology. On the one hand, we get a number of opportunities and benefits, on the other hand, we can suffer losses. The topic of globalization is at present the most up-to-date, so it was approached in the context of China because the Chinese are promoting themselves as the leader in globalization. The Chinese are developing through the use of the noble ideas of economic freedom developed by Western societies and experienced through isolationism, nationalism and communism. They adopt and use only those ideas that make it possible to achieve an economic and political advantage. History teaches us that new empires developed best on the ruins of previous ones. It would appear that we have a similar situation today, although decisive events may be yet to occur.

The contemporary Chinese state is a unique creation with a huge territory, an enormous population, and a specific socio-economic system. Thanks to the opening of their own 
economy to free-floating Western capital, the Chinese have gained access to modern technologies and proven management culture. It is due to this that their economy has achieved high efficiency and enabled the development of global corporations. This has also happened in an extremely short period of time. The presented glimpse into globalization is not the only way to analyze it. In the context of globalization and problems oscillating around this topic, it is worth to read the articles: Acemoglu et al. (2017), Borjas et al. (2018), Bond and Lang (2018), Elsner and Isphording (2018), Llull (2017), Theoharides (2018) Wiswall and Zafar (2017).

In further studies, may be applied, the proposed method for the analysis of the relationship between the different regions in the context of a multi-dimensional, taking into account macroeconomic indicators and determine the best extension for a series of related. Research has shown that globalization is very important, it gives a lot of possibilities.

\section{References}

Acemoglu, D., Egorov, G. \& Sonin, K. (2017). Social mobility and stability of democracy: reevaluating de tocqueville. The Quarterly Journal of Economics, 133(2), 1041-1105.

Borjas, G.J., Doran, K.B. \& Shen, Y. (2018). ethnic complementarities after the opening of china how chinese graduate students affected the productivity of their advisors. Journal of Human Resources, 53(1), 1-31.

Bond, T.N. \& Lang, K. (2018). The Black-White education scaled test-score gap in Grades K-7. Journal of Human Resources, 53(4), 891-917.

Cohen, A., Daubechies, I. \& Vial, P. (1993). Wavelets on the interval and fast wavelet transforms. Applied and computational harmonic analysis, 1(1), 54-81.

Dreher, A. (2006). Does globalization affect growth? Evidence from a new index of globalization. Applied Economics, 38(10), pp. 1091-1110.

Elsner, B. \& Isphording, I.E. (2018). Rank, sex, drugs, and crime. Journal of Human Resources, 53(2), 356-381.

Keohane, R.O. \& Nye, J.S. (2000). Introduction'in Joseph S. Nye and John D. Donahue. Governance in a Globalizing World, 64-74.

Hadaś-Dyduch, M. (2015a). Prediction of wavelets analysis. Financial Management of Firms and Financial Institutions, Proceedings of the 10th International Scientific Conference: 341-348, Ostrava, Czech Republic.

Hadaś-Dyduch, M. (2015b). Polish macroeconomic indicators correlated-prediction with indicators of selected countries. Proceedings of the 9th Professor Aleksander Zelias International Conference on Modelling and Forecasting of Socio-Economic Phenomena: 68-76, Cracow, Poland.

Hadaś-Dyduch, M. (2016a). Econometric-wavelet prediction in spatial aspect. Proceedings of the 10th Professor Aleksander Zelias International Conference on Modelling and Forecasting of Socio-Economic Phenomena: 45-52, Cracow, Poland.

Hadaś-Dyduch M. (2016b). Globalization in the context of cointegration selected countries. Proceedings of the 16th International Scientific Conference Globalization and its Socio-Economic Consequences, Conference Proceedings: pp. 587-594, Rajecke Teplice, Slovak Republic.

Hadaś-Dyduch, M. (2016c). Model-spatial approach to prediction of minimum wage Proceedings of the International Scientific Conference on Quantitative Methods in Economics - Multiple Criteria Decision Making XVIII: 134-138, Vratna, Slovakia.

Hadaś-Dyduch, M., Pietrzak, M.B. \& Balcerzak, A.P. (2016). Wavelet analysis of unemployment rate in Visegrad Countries. Proceedings of the 16th International Scientific Conference on Globalization and its SocioEconomic Consequences: 595+-Rajecke Teplice, Slovak Republic.

Hadaś-Dyduch, M. (2017). Analysis of globalization by wavelets through the prism of selected Euro Area Countries. Proceedings of the 17th International Scientific Conference Globalization and Its Socio-Economic Consequences: 605-612, Rajecke Teplice, Slovak Republic.

Llull, J. (2017). The effect of immigration on wages: exploiting exogenous variation at the national level. Journal of Human Resources, 0315-7032R2.

Norris, P. (2000). Global governance and cosmopolitan citizens. Governance in a globalizing world, 1-27.

Shensa, M. J. (1992). The discrete wavelet transform: Wedding the a Trous and Mallat algorithms. IEEE Transactions on signal processing, 40(10), 2464-2482. 
Theoharides, C. (2018). Manila to Malaysia, Quezon to Qatar international migration and its effects on origincountry human capital. Journal of Human Resources, 53(4), 1022-1049.

Wickerhauser, M.V. (1994). Adapted wavelet analysis from theory to software. IEEE press.

Wiswall, M. \& Zafar, B. (2017). Preference for the workplace, investment in human capital, and gender. The Quarterly Journal of Economics, 133(1), 457-507. 